\title{
Cutout Reinforcements for Shear Loaded Laminated and Sandwich Composite Panels
}

\author{
S.J. Guo ${ }^{\dagger}$ \\ School of Engineering, Cranfield University, Bedfordshire, MK43 0AL, UK \\ L. Zhou and C.W. Cheung \\ School of Engineering and Mathematical Sciences, City University, London, EC1V 0HB, UK
}

\section{SYNOPSIS}

This paper presents the numerical and experimental studies of shear loaded laminated and sandwich carbon/epoxy composite panels with cutouts and reinforcements aiming at reducing the cutout stress concentration and increasing the buckling stability of the panels. The effect of different cutout sizes and the design and material of cutout reinforcements on the stress distribution and buckling behaviour of the panels are evaluated. The finite element method and an analytical method are employed to perform parametric studies. The analysis of the panels under simply supported and clamped conditions has been conducted and compared. The results from both constant stress and constant displacement shear loading cases are in very good agreement with those obtained from testing of the composite panels with selected cutout reinforcements. Conclusions are drawn on the cutout reinforcement design and improvement of stress concentration and buckling behaviour of shear loaded laminated and sandwich composite panels with cutouts.

\section{Introduction}

It is well known that laminated composite materials are increasingly used in aircraft structures for their great potential to achieve structural design tailoring in specific stiffness and strength, weight saving and desirable mechanical behaviour against applied loads. However, cutouts are often necessary in the construction of aircraft structures for lightening holes, passages for wire bundles, hydraulic and fuel pipes, control linkages, accessibility for final assembly and maintenance inspections. In the construction, cutout usages are categorised (Niu, 2001) and the most noticeable feature of cutout for metallic structure is the rounding of the corners to prevent excessively high stress concentrations.

Aircraft engineers view cutouts in airframe structures with disfavour because they cause reduction in strength and stiffness and the necessary reinforcement increases cost and weight to the overall design. In addition, the design of reinforcement is a difficult task since it is a problem area for both static and fatigue strengths and there is insufficient design data especially with regard to composite structures. To ensure structural integrity around a cutout in composite structures, two approaches are currently used. Firstly, the thickness of the structural element is increased uniformly across its entire surface such that the resulting stress concentration is no longer a problem but there is a corresponding increase in structural weight. Alternatively, the structure may be locally modified with the goal of achieving either a reduction in the local stress concentration or a minimum possible increase in structural strength. An ideal local reinforcement would result in minimising the mass penalty of overall

\footnotetext{
${ }^{\dagger}$ Corresponding author (s.guo@cranfield.ac.uk)
} 
reinforcement as well as reducing the stresses around the cutout under the same design constraints.

The problems of stress concentration and bucking behaviour due to cutouts in laminated composite plates have been studied by a number of researchers since the early 1970s (Greszczuk, 1971; Martine, 1972) and there is an excellent review of research work in these areas (Nimesh, 1996). However, there was a need for more studies on shear-loaded composite panels with cutouts (Turvey, 1988; Owen, 1990; Britt, 1993) and more comparison with experimental data to substantiate analytical results (Rouse, 1990). Experimental verification is also necessary to provide confidence among structural designers and promote innovative designs in using composite materials. Since then increasing studies have been conducted on the buckling behaviour of composite plates under combined loadings (Kim, 1996) and cutout reinforcements. For example, some authors (Eiblmeier and Loughlan, 1995) investigated the buckling response of a shear-loaded carbon/epoxy panel with bonded rings for cutout reinforcement. In another numerical study of stress concentration and stability of shear-loaded composite plates (Pandey, 2001), flanged cutout reinforcement adapted from metallic cutout reinforcement was designed and analysed. The authors found that the composite plates with flanged cutouts could provide significant weight saving in reinforcement design. This type of reinforcement has been amenable to numerical simulation, albeit difficult to fabricate in practice especially for carbon/epoxy composite panels. In addition, analytical methods have been developed for engineering analysis of laminated composite plates with cutouts and limited laminate layups (ESDU- 85001, 86003, 75034 and 80023). Compared with laminated composite plates, it is noted that much less attention has been paid to the study of cutout effect on composite faced sandwich panels (Hadi, 1995).

The objective of this paper is to present a study on various cutout reinforcement designs and their effect on the stress concentration and buckling behaviour of laminated and sandwich composite panels with cutouts. The shear-loaded panels made of carbon/epoxy composites with circular cutouts of different sizes have been studied in detail and their results are compared. For the laminated composite panels, the design analysis is focused on local reinforcement around the cutouts to reduce the stress concentration as well as to increase the buckling loads with weight consideration. Therefore, these reinforcement types such as rings or flanges, which have been widely adopted for metallic structures and had some success with compression-loaded composite plates, are considered for the shear-loaded composite panels. For the sandwich panels, the design analysis deals with buckling and stress concentration concerns in two stages. First the study is focused on obtaining an optimal combination of the composite face and core thickness for the maximum buckling stability subject to the same weight as the laminated composite panel. The study is then focused on reducing the cutout stress concentration, which is more of a concern to cutout reinforcement. The scope of this investigation includes analytical study, numerical simulation using finite element method (FEM) and experimental work for modelling validation. Parametric study has been carried out as part of the overall investigation. The results of the analysis for the panels subjected to constant stress and constant displacement loading agree very well and their comparison with the experimental results also shows a very good agreement.

\section{Theoretical and Numerical Methods}

So far there is no theoretical method for an exact solution of stress at the cutout edge of a composite laminate. However the method developed by Greszczuk (Greszczuk 1971) can produce an elastic stress distribution around the perimeter of a circular cutout in thin 
homogeneous orthotropic plates under a combination of in-plane loadings. When applied to a single ply lamina, this method gives an approximate result.

Based on the theory, the tangential stress $\sigma_{\theta}$ at an angular position $\theta$ measured from horizontal axis in fibre direction 1 for a fibre reinforced composite ply subjected to a combination of bi-axial and shear stresses is approximated by the following equation

$$
\sigma_{\theta}=\frac{\left(\sigma_{1}+\sigma_{2}\right) \lambda_{1}-\left(4 \sigma_{2}\right) \lambda_{2}+\left(4 \tau_{12}\right) \lambda_{3}}{\left(1+\gamma_{1}^{2}-2 \gamma_{1} \cos 2 \theta\right)\left(1+\gamma_{2}^{2}-2 \gamma_{2} \cos 2 \theta\right)}
$$

where $\sigma_{1}, \sigma_{2}, \tau_{12}$ represents the remotely applied ply stresses in direction 1,2 and shear; and

$$
\begin{aligned}
& \lambda_{1}=\left(1+\gamma_{1}\right)\left(1+\gamma_{2}\right)\left(1+\gamma_{1}+\gamma_{2}+\gamma_{1} \gamma_{2}-2 \cos 2 \theta\right) ; \lambda_{2}=\gamma_{1}+\gamma_{2}-\left(1+\gamma_{1} \gamma_{2}\right) \cos 2 \theta \\
& \lambda_{3}=\left(\gamma_{1} \gamma_{2}-1\right) \sin 2 \theta
\end{aligned}
$$

The constants in the above expressions are defined as follows

$$
\gamma_{1}=\frac{\sqrt{\left\{A+\sqrt{A^{2}-\left(E_{2} / E_{1}\right)}\right\}}-1}{\sqrt{\left\{A+\sqrt{A^{2}-\left(E_{2} / E_{1}\right)}\right\}}+1} ; \gamma_{2}=\frac{\sqrt{\left\{A-\sqrt{A^{2}-\left(E_{2} / E_{1}\right)}\right\}}-1}{\sqrt{\left\{A-\sqrt{A^{2}-\left(E_{2} / E_{1}\right)}\right\}}+1} ; \quad A=\left[\frac{E_{2}}{2 G_{12}}-v_{21}\right]
$$

According to Greszczuk, the above method for one ply can be extended to an infinite composite laminate having a central hole by considering the whole laminate acting effectively as a single ply. This can be performed by conducting a coordinate transformation and replacing ply properties by equivalent elastic properties of a laminate.

Therefore the tangential stress at an angular position $\alpha$ measured from the horizontal $\mathrm{x}$-axis for a laminate subjected to a combination of bi-axial and shear loading can be expressed by

$$
\sigma_{\alpha}=\frac{\left(\sigma_{x}+\sigma_{y}\right) \bar{\lambda}_{1}-\left(4 \sigma_{y}\right) \bar{\lambda}_{2}+\left(4 \tau_{x y}\right) \bar{\lambda}_{3}}{\left(1+\beta_{1}^{2}-2 \beta_{1} \cos 2 \alpha\right)\left(1+\beta_{2}^{2}-2 \beta_{2} \cos 2 \alpha\right)}
$$

where $\sigma_{x}, \sigma_{y}, \tau_{x y}$ represents the remotely applied in-plane stresses; and

$$
\begin{aligned}
& \bar{\lambda}_{1}=\left(1+\beta_{1}\right)\left(1+\beta_{2}\right)\left(1+\beta_{1}+\beta_{2}+\beta_{1} \beta_{2}-2 \cos 2 \alpha\right) ; \bar{\lambda}_{2}=\beta_{1}+\beta_{2}-\left(1+\beta_{1} \beta_{2}\right) \cos 2 \alpha ; \\
& \bar{\lambda}_{3}=\left(\beta_{1} \beta_{2}-1\right) \sin 2 \alpha
\end{aligned}
$$

The constants in the above expressions for Greszczuk's laminate theorem are defined as

$$
\beta_{1}=\frac{\sqrt{\left\{B+\sqrt{B^{2}-\left(E_{y} / E_{x}\right)}\right\}}-1}{\sqrt{\left\{B+\sqrt{B^{2}-\left(E_{y} / E_{x}\right)}\right\}}+1} ; \quad \beta_{2}=\frac{\sqrt{\left\{B-\sqrt{B^{2}-\left(E_{y} / E_{x}\right)}\right\}}-1}{\sqrt{\left\{B-\sqrt{B^{2}-\left(E_{y} / E_{x}\right)}\right\}+1}} ; \quad B=\left[\frac{E_{y}}{2 G_{x y}}-v_{y x}\right]
$$

In theory, this method is only valid for a laminate of layup without in-plane coupling between the axial and shear stiffness. It is limited to a symmetric, balanced, especially orthotropic laminate. Based on the assumption of constant strain through the thickness, the cutout diameter should be greater than five times of the laminate thickness. In addition, the distance from the cutout edge to the plate boundary should be greater than 1.5 times of the cutout diameter for sufficient accuracy. Despite of all these limits, this method provides a useful and convenient tool for predicting an average stress and strain through the thickness of a laminate 
at its cutout edge. Based on the method, a program has been developed for industrial application (MIL-HDBK, 1998) and it is employed for the analysis in this paper. Some detail of the method is available in ESDU 85001 and a computer program based on the method is available in ESDU 86003.

For numerical simulation, MSC PATRAN/NASTRAN as a well developed commercial FEM tool has been employed in this investigation for its applicability to such a problem.

\section{Composite Panel Examples and FE Modelling}

In this paper, three examples from the two types of composite panels have been considered for analysis and experiment.

Example 1 is a square laminated composite plate of size $\mathrm{a}=320 \mathrm{~mm}$ and thickness $\mathrm{t}=2 \mathrm{~mm}$ with a central circular cutout of diameter d varying from 32 to $160 \mathrm{~mm}$ as illustrated in Figure 1. The plate is made of 16-ply carbon/epoxy prepreg (913C-HTA) with laminate layup $\left[( \pm 45)_{4}\right]_{\mathrm{s}}$ and material properties listed in Table 1 .

Example 2 is a square sandwich panel of the same dimension and cutout sizes as example 1. It is made of two skin faces of 8-ply $\left[( \pm 45)_{2}\right]_{\mathrm{s}}$ laminate of the same carbon/epoxy material as example 1 and an AIREX C71 foam core of properties listed in Table 1. The datum thickness of the skin face and the core is $1 \mathrm{~mm}$ and $5 \mathrm{~mm}$ respectively.

Example 3 is a square sandwich panel of size a $=280 \mathrm{~mm}$ with carbon/epoxy prepreg (Hexply M21/35\%/268/T800s) for the faces and a $5 \mathrm{~mm}$ thick AIREX C75.71 foam core of properties listed in Table 1. A central circular cutout diameter varies from $\mathrm{d}=36$ to $140 \mathrm{~mm}$. The datum thickness of the skin face and core is $2 \mathrm{~mm}$ and $5 \mathrm{~mm}$ respectively.

A MSC NASTRAN FE model for the composite laminated plate is created using QUAD4 shell element in composite laminate type. A mesh density of 2400 elements for the panel model has been chosen for efficient computation and sufficient accuracy in the subsequent laminate panel analysis since further doubling of the mesh density would only increase the accuracy of the stress results by less than $1 \%$. For the sandwich panels, the same shell element type as above is selected for the laminate faces and a HEX-8 solid element type is used for the core model.

\section{Analysis of Laminated Composite Plates with a Central Circular Cutout}

\subsection{Cutout Size Effect on the Maximum Stress}

In order to study the cutout effect on the maximum stress occurring at the cutout edge of a shear-loaded composite plate, the example 1 plate is simply supported and subjected to a shear load of $S=20 \mathrm{~N} / \mathrm{mm}$ along all edges of the plate. The MSC.NASTRAN FE numerical results of maximum stress of the panel against a range of cutout size ratio are obtained. Although the stress results in each layer and different directions have been calculated, only the maximum principle stresses in the fibre direction of 45-degree ply have been plotted in Figure 2. It is noted that the maximum principle stress varies almost linearly with $(d / a)^{2}$, indicating that the stress is approximately proportional to the ratio of the circular cutout area to square panel area over the range of cutout sizes considered in this investigation. 
To compare the FE results with the analytical method in ESDU 85001, the equivalent elastic modulus of the laminate through thickness has been calculated and used in the ESDU datasheet and also used to create a quasi-isotropic FE model. Their resulting normal stress $\sigma_{\mathrm{x}}$ in $\mathrm{x}-$ and $\sigma_{\mathrm{y}}$ in $\mathrm{y}$-axis for the plate with a cutout of diameter $\mathrm{d}=44 \mathrm{~mm}(\mathrm{~d} / \mathrm{a}=0.1375)$ are listed in Table 2. The tensile and compressive stresses in opposite sign are located at the two angular positions $\mathrm{A}$ and $\mathrm{B}$ around the cutout differing by 90 degrees as shown in Fig.7. In order to compare the above stresses with the laminate FE results, an average stress $\sigma_{\mathrm{x}}$ is calculated by taking an average value of the stress from all the plies of the laminate. Similarly an average stress $\sigma_{\mathrm{y}}$ in $\mathrm{y}$-direction is also calculated for the laminate. The laminate FE stresses are also in opposite sign at the two angular positions A and B. The laminate FE stresses show clearly a better agreement with the ESDU results than with the quasi-isotropic FE model.

For larger cutout diameters, the difference in the stress results between the FE model and the ESDU data is slightly larger than that for $\mathrm{d}=44 \mathrm{~mm}$. However since the approximate ESDU data does not take the cutout size into account, a poorer agreement between the ESDU data and FE results is expected when the cutout diameter increases to higher values.

\subsection{Cutout Size Effect on the Plate Buckling Stability}

As the cutout size and stress at the cutout edge increase, a reduction in plate buckling stability is expected. In the analysis, a buckling load factor (BLF), which is defined as a ratio of critical buckling load of the plate against the applied load is used to present the plate buckling stability. For the example 1 laminate plate under a simply-supported (s-s) or clamped condition and a shear load $\mathrm{S}=20 \mathrm{~N} / \mathrm{mm}$, the buckling load results up to the first five modes by FEM have been calculated. It is noted that the BLF for all the modes vary in a similar trend against the cutout size. The effect of cutout size on laminate stability can be seen by presenting the BLF in the first mode against the cutout ratio $d / a$ as shown in Figure 3 . It is also noted that the composite plate buckles when the cutout ratio $\mathrm{d} / \mathrm{a}$ approaches 0.3 under the applied shear load. For comparison, the value for the laminate plate without cutout, $B L F=1.8$, obtained from ESDU 80023 datasheet is also included in Figure 3 although the result is approximate since the ESDU data apply only to a specially orthotropic plate.

\subsection{Cutout Size Effect on Damage Tolerance}

Although the fatigue behaviour of laminated composites is generally much better than metallic materials, damage tolerance is a major concern in the design of a laminated composite structure. To make sure a composite structure has adequate tolerance to impacts and manufacture defects, the ultimate strain is normally limited up to $4000 \mu \varepsilon$ in aircraft design. As the stress and strain increase with the cutout ratio, the buckling stability decreases. When the cutout ratio reaches 0.3 for the simply supported laminate panel, Fig. 3 shows a resulting $\mathrm{BLF}=0.91$, which indicates the panel buckling under the applied load. However the associated maximum principle stress of $127 \mathrm{MPa}$ is less than $10 \%$ of the ultimate stress. It is well below fatigue allowable stress level, hence leads to little crack propagation. On the other hand, the maximum normal and shear strain at the cutout edge is $1350 \mu \varepsilon$ and $2036 \mu \varepsilon$ respectively, which is well below the allowable damage tolerance level. Therefore the buckling stability is the primary concern in the current cutout and reinforcement study. 


\section{Cutout Reinforcements Analysis using FEM}

Four of the five different types of cutout reinforcements as illustrated in Figure 4 have been investigated for their effectiveness in reducing stress concentration and improving stability of the example 1 composite plate. These reinforcements include a flanged cutout (Type 1), a composite ring (Type 2), a flanged cutout plus a composite ring (Type 3 ) and a double ring on each side of the laminate (Type 4).

To simplify the presentation, only the maximum principle stress results from cutout diameter $44 \mathrm{~mm}(\mathrm{~d} / \mathrm{a}=0.1375)$ and the $1^{\text {st }}$ mode BLF against three different cutout ratios obtained for the composite plate are shown in the following tables for each of four reinforcement types. For easy comparison, all values of stress and BLF tabulated in the Tables 3-6 for the four types of reinforcement are normalised with respect to their corresponding un-reinforced values plotted in Figures 2 and 3.

Type 1 - Flange Reinforcement

In the first reinforcement type, the effect of flange angle $\phi$ and height $h$ on the maximum stress at the cutout edge and the reinforced plate stability has been studied. Table 3 shows that the maximum stress in fibre direction has been reduced by up to $16.5 \%$ for composite plate at the cost of adding flange weight equivalent to $1 / 3$ of the cutout material mass. The results also show that flange reinforcement provides a progressive improvement in stability as cutout ratio increases although the unsymmetrical geometry in z-direction may cause a shear-bending coupling and reduce the reinforcement effectiveness in stability improvement.

\section{Type 2 - Single Ring Reinforcement}

In the type 2 reinforcement, a composite ring of the same material and layup as the laminate plate but of different widths and thicknesses is added on one side of the laminate plate around the cutout. As shown in Table 4, this reinforcement results in a stress reduction by up to $18.4 \%$. Overall the plate stability is slightly better with this type of reinforcement compared with type 1 reinforcement. However the reinforcement causes a weight penalty equivalent to 2.6 times of the cutout material mass and the unsymmetrical geometry in z-direction may also reduce the reinforcement effectiveness in improving stability.

Type 3 - Flange and Ring Reinforcement

In the third type, a composite ring of width $\mathrm{w}_{\mathrm{r}}=20 \mathrm{~mm}$ and $\mathrm{t}_{\mathrm{r}}=2 \mathrm{~mm}$ is added onto the laminate in the opposite side to the flanged cutout of type 2 as shown in Figure 4. This hybrid reinforcement results in a reduction of stress by up to $30.3 \%$, as shown in Table 5 . The reinforcement also provides a much better stability for the plates with the largest cutout, but no better for the smaller cutout sizes when comparing with results obtained for reinforcement types 1 and 2 . In addition, a weight penalty equivalent to 2.6 times of the cutout material mass is added.

\section{Type 4 - Double ring reinforcement}

In the fourth type, reinforcement rings of different sizes and materials may be bonded on both sides of the laminated plate around the cutout. When a couple of composite rings same as that in Type 2 is used, significantly more reduction in stress at the cutout edge and increase in BLF especially for the largest cutout size has been achieved as shown in Table 6 when comparing with results of previous reinforcement types.

When a couple of metallic rings of width $\mathrm{w}_{\mathrm{r}}=15 \mathrm{~mm}$ and $\mathrm{t}_{\mathrm{r}}=2 \mathrm{~mm}$ are used instead of the composite rings, more stress reduction can be achieved depending upon the ring materials as 
shown in Table 7. From the stress comparison of all the reinforcement types shown in Figure 5 below, it is noted that the metallic ring reinforcement is most effective.

The above numerical analysis clearly shows that type 4 double ring reinforcement results in the greatest reduction of stress around the cutout and stability improvement. Regarding the ring materials, it is noted that the higher the material modulus the more load the ring will carry hence the less stress remains in the laminate near the cutout.

\section{Analysis of composite sandwich panels}

The analysis for the example 2 composite sandwich panel has also been conducted by using FE method. Table 8 shows the maximum stress and the $1^{\text {st }}$ BLF against cutout ratio for the example 1 plate with two selected types of reinforcement designs as well as the example-2 sandwich panel. Similar to those in Tables 3-6, all values presented in Table 8 except the stress in the core are normalised with respect to the maximum stress and BLF values calculated for the original un-reinforced laminated composite plate in example 1.

The results in Table 8 indicate that, comparing with the laminated composite plate (example 1) even with the most effective steel ring reinforcement, the composite sandwich panel (example 2) without reinforcement is by far more effective in buckling stability. However a little increase of the maximum stress and weight raises design concerns although the stress increase is less than $10 \%$ and the weight penalty is minimal.

Further analysis has been carried out on the composite sandwich panel buckling stability with a range of combinations of composite face and core thickness while keeping the panel weight the same as the un-reinforced laminated composite plate. The $1^{\text {st }}$ mode BLF results as shown in Table 9 indicate three interesting points. Firstly the sandwich panel is more effective against buckling than the laminated plate of the same weight if the face laminate has 4 or more plies; secondly although there is a face thickness limit below which the sandwich panel could be worse than the laminated plate against buckling, the buckling stability of a sandwich panel is not proportional to its composite face thickness; in fact there is an optimal combination of face-core thickness $(0.75-13-0.75 \mathrm{~mm})$ for the greatest buckling stability that has been obtained in the analysis. The above results indicate that a proper design for a sandwich panel with cutouts will improve the buckling stability significantly without weight penalty.

Regarding the stress however, Table 8 shows that the sandwich offers little advantage to reducing the maximum stress at the cutout edge. The stress concentration in the laminated face at cutout remains a concern for cutout reinforcement consideration. Table 8 also shows that the maximum von Mises stress in the core is only $0.14 \mathrm{MPa}$ for the cutout ratio 0.5 panel. This is well below the foam material ultimate normal stress of $1.4 \mathrm{MPa}$ and shear stress of 1.0 $\mathrm{MPa}$. Therefore it is the buckling capability rather than the material or bonding failure that concerns the panel cutout reinforcement design in the current study.

In this investigation, a sandwich panel as the example 3 was manufactured and tested with details given in the next section. In order to use the test data to validate the numerical analysis, a FE model for the sandwich panel has been created to focus on cutout stress analysis. The numerical model is started with a $1 \mathrm{~mm}$ composite face with three types of cutout reinforcement: a central tube type 5 as illustrated in Figure 4, a single ring and double sided rings made of Al-7075 similar to the type 2 and 4 in Figure 4. Subjected to a simply supported condition and a shear load $\mathrm{S}=20 \mathrm{~N} / \mathrm{mm}$ along the edges of the panel, the maximum stress results at the cutout edge for three different cutout size ratios and reinforcement types 
are shown in Figure 6. In this case, the selected reinforcement tube and ring thickness is $t_{r}=2$ $\mathrm{mm}$ and the ring width is $20 \mathrm{~mm}$.

From the above results, three interesting points are noted. Firstly, similar to the laminated composite plate, the double ring reinforcement type 4 is the most effective one and the maximum stress can be reduced by over $50 \%$ for the three cutout sizes. Secondly a single ring reinforcement can also significantly reduce the maximum stress by $12-22 \%$ for the different cutout sizes; the central tube reinforcement type 5 is very effective for small cutout $\mathrm{d} / \mathrm{a}=0.13$, but much less effective for larger cutouts. Finally, for the example 3 un-reinforced sandwich panel having a skin face thickness $\mathrm{t}=2 \mathrm{~mm}$ and cutout diameter $\mathrm{d}=60 \mathrm{~mm}$, the FE results show that the maximum tensile stress on the laminate surface in -45-degree direction is $38 \mathrm{MPa}$ and when the cutout is reinforced by inserting a central tube of thickness $t_{r}=2 \mathrm{~mm}$ and depth $t=9$ $\mathrm{mm}$, the maximum surface stress in the same position and direction is reduced to $25.5 \mathrm{MPa}$. The results agree with test data very well as presented in the next section.

\section{Experiment of CFRP Plates with Cutout Reinforcements}

\subsection{Test Samples}

To validate the above FE results, a few reinforcement design cases from the above examples have been selected for experimental tests. For the example 1, three laminated composite plates with circular cutout of diameter $\mathrm{d}=44 \mathrm{~mm}$ and reinforcement types 2 and 4 have been manufactured as test samples 1-4 with details listed in Table 10. For the example 3, two sandwich panels having a circular cutout of $\mathrm{d}=60 \mathrm{~mm}$ with and without a central tube reinforcement have been manufactured as test samples 5 and 6 as listed in Table 12.

The laminate sample was made of 16-ply (913C-HTA) unidirectional prepreg with a stacking sequence of $\left[(+45 /-45)_{4}\right]_{\mathrm{s}}$ and the cutout was made after curing. Both the metallic rings and the CFRP rings were manufactured separately and then bonded to the cured laminated plate using Huntsman Araldite 420 A/B two component epoxy paste adhesive.

For the test samples 1,5 and 6, four rosette strain gauges were placed close to the cutout edge at $45^{\circ}$ and $135^{\circ}$ from the $\mathrm{x}$-axis on both sides of the plate surface as illustrated in Figure 7. For sample 2, rosette gauges of factor 2.11 were located as shown in Figure 8 since it was unable to place them near the cutout edge or on the narrow ring on the reinforced back side. For sample 3 where CFRP rings were bonded on both sides, all rosette gauges were located outside the ring with additional two small strain gauges of size $6 \mathrm{~mm}$ and gauge factor 1.88 glued on the ring at an angle of $45^{\circ}$ as illustrated in Figure 9a. For test sample 4 however, all rosette strain gauges were conveniently placed near the cutout edge on the ring of $15 \mathrm{~mm}$ wide as shown in Figure 9b.

\subsection{Test Rig and Loading}

A test machine RDP Avery, which may apply loading up to $600 \mathrm{kN}$ was selected. A shear test rig made of steel was designed and manufactured as shown in Figure 10. The test rig was mounted to the machine at the bottom of the jig. The test sample plate was bolted to the test rig along one vertical edge and loaded downward along the opposite edge as shown in Figure 10. To prevent the laminated composite plate from buckling before the loading reaches 6.4 $\mathrm{kN}$, which is equivalent to a shear load intensity of $20 \mathrm{~N} / \mathrm{mm}$, the top and bottom edges of the plate were reinforced by bolting steel strips on both sides. 


\subsection{Test Results and Data Analysis}

The relationship between measured voltage from the strain gauges and strain $\varepsilon=\mu \times 10^{3}$ is given by (Eiblmeier, 1996):

$$
\frac{\Delta V}{V}=\frac{G F^{*} \varepsilon^{*} 10^{-3}}{4}
$$

where $\Delta \mathrm{V}$ is the differential gauge voltage, $\mathrm{V}$ bridge excitation voltage (used 5.0 V), GF is the gauge factor, and $\varepsilon$ the surface strain experienced by strain gauge.

After a gain of $10^{3}$ is applied to the test data, the surface strain $\varepsilon$ can be expressed as:

$$
\varepsilon=\frac{\Delta V^{*} 4}{V^{*} G F}
$$

From the measured strains, the stresses at the measurement locations of the test plate can be calculated based on the following equations (ESDU 85001).

$$
\begin{aligned}
& \sigma_{x}=\frac{E_{x}}{\left(1-v_{x y} v_{y x}\right)} \varepsilon_{x}+\frac{v_{y x} E_{x}}{\left(1-v_{x y} v_{y x}\right)} \varepsilon_{y} \\
& \sigma_{y}=\frac{v_{x y} E_{y}}{\left(1-v_{x y} v_{y x}\right)} \varepsilon_{x}+\frac{E_{y}}{\left(1-v_{x y} v_{y x}\right)} \varepsilon_{y}
\end{aligned}
$$

$\underline{\text { Sample } 1}$ For the laminate plate without reinforcement, strains against loadings measured at point $\mathrm{B}$ are presented in Figure 11. The strains corresponding to loading $6.4 \mathrm{kN}$, which gives $20 \mathrm{~N} / \mathrm{mm}$ shear force along the edge were recorded and converted to stress $\sigma_{\mathrm{x}}=76 \mathrm{MPa}$ as shown in Table 11. Since the strain measured is actually from the local region a few millimetres away from the cutout edge at point $\mathrm{B}$ as illustrated in Figure 7, the FE result taken for comparison should be in the same position. As shown in Figure 12, the stress in that region varies from $72 \mathrm{MPa}$ to $91 \mathrm{MPa}$ and the average is $\sigma_{\mathrm{x}}=81.5 \mathrm{MPa}$, which agrees well with the test data. An alternative FE solution based on constant displacement loading condition results in an average stress $72.3 \mathrm{MPa}$, which gives a slightly better comparison.

Sample 2 For the laminated composite plate with a CFRP ring reinforcement, strains measured at point $\mathrm{D}$ as illustrated in Figure 8 are presented in Figure 13. The strains corresponding to $6.4 \mathrm{kN}$ loading were converted to stress $\sigma_{\mathrm{x}}=45.1 \mathrm{MPa}$ as shown in Table 13 . Comparing the measured stress with the corresponding FE results of $40.1 \mathrm{MPa}$ based on constant load and $41.8 \mathrm{MPa}$ based on constant displacement calculation, it is noted again the agreement is good.

$\underline{\text { Sample } 3}$ For the laminate plate with double composite ring reinforcement under the same loading $6.4 \mathrm{kN}$, strains measured at point D (see Figure 9(a)) are shown in Figure 14 and the resulting stress are also listed in Table 11. The results also show a very good agreement between the test data and FE results.

Sample 4 For the laminate plate with steel ring reinforcement, strains measured at point B on the ring (see Figure 9b) are presented in Figure 15. The strains and the resulting stress are also listed in Table 13. The stress on the ring from FE result based on constant shear loading varies 
in the measurement region and the average stress is about 23.7 MPa. The FE stress based on constant displacement is $24 \mathrm{MPa}$ which is also very close to the test data.

For the above four test samples, buckling loads from experiment and FE results in simply supported condition as shown in Table 12 also agree very well.

Samples 5 and 6 The sandwich panel test by applying a shear load up to $11 \mathrm{kN}$ was repeated three times. The strain measurements at point B (see Figure 7) under the shear loading $5.6 \mathrm{kN}$ $(20 \mathrm{~N} / \mathrm{mm})$ are averaged and converted to a principle stress $\sigma_{\mathrm{p}}=30.4 \mathrm{MPa}$ for sample 5 and $\sigma_{\mathrm{p}}=20.4 \mathrm{MPa}$ for sample 6 test respectively. On the other hand, the FE results show that the maximum principle stress at the point $\mathrm{B}$ measurement region varies from 28 to $38 \mathrm{MPa}$ for sample 5 and from 19 to $25 \mathrm{MPa}$ for sample 6 . The results in average maximum principle stresses of $33 \mathrm{MPa}$ and $22 \mathrm{MPa}$ and only $8.5 \%$ and $7.8 \%$ differences for samples 5 and 6 respectively compared to the test data.

\section{Conclusions}

The above FE results have shown that the maximum stress and buckling stability are strongly influenced by the cutout size for both laminated and sandwich composite panels. The maximum principle stress at the cutout edge varies approximately linearly with the area ratio of the circular cutout and the plate whereas the buckling load factor varies approximately linearly with the appreciable cutout ratio. It is clear from the present study that an optimal combination of face and core thickness can be determined for a shear loaded sandwich panel to gain the maximum buckling stability without weight penalty. However, the sandwich panel suffers similar stress concentration problem for a given cutout ratio comparing to the laminated composite plate. Parametric study carried on the different reinforcement types shows that double ring reinforcement is the most effective reinforcement design for both composite plates and sandwich panels. Further analysis of the double-ring reinforcement type with different ring materials shows that double steel rings can be used to reduce even further the maximum plate stress at the cutout edge albeit with some additional weight penalty. It is clear that the most effective means of improving the buckling stability of composite panels without weight penalty is to employ sandwich design, and the most effective reinforcement for reducing sandwich panel stress concentration at minimum weight cost is the central tube design.

Comparison of the stress and buckling results between the constant stress and the constant displacement loaded panels has shown a good agreement. The FE results have been validated by experimental test data and the overall agreement between them is very good.

\section{References}

1. Niu, M. C. Y. Airframe Stress Analysis and Sizing, $2^{\text {nd }} e d$. Hong Kong Conmilit Press Ltd, Hong Kong. Chapter 13, 2001.

2. Greszczuk, LB. Stress concentrations and failure criteria for orthotropic and anisotropic plates with circular openings. ASTM STP 497, 1971. pp. 363-381.

3. Martine, James: Buckling and postbuckling of laminated composite square plates with reinforced central holes, PhD Diss., Case Western Reserve University, 1972.

4. Nemeth, M.P., Buckling and postbuckling behaviour of laminated composite plates with a cutout, NASA Technical Paper 3587, July 1996. 
5. Turvey, GJ and Sadeghipour, K. Shear buckling of anisotropic fibre-reinforced rectangular plates with central circular cutouts. Computer Aided Design in Composite Material Technology Proc. Internat. Conf. CA Brebbia, WR Blain, and WP De Wilde, eds., Apr. 1988, pp. 459-473.

6. Owen, VL, Klang, EC. Shear buckling of specially orthotropic plates with centrally located cutouts. In: Eighth DOD/NASA/FAA Conference on Fibrous Composites in Structural Design, Part 2, Sept. 1990, pp. 695-706.

7. Britt, VO. Shear and compression buckling analysis for anisotropic panels with centrally located elliptical cutouts. Proc. 34th AIAA/ASME/ASCE/AHS/ASC Structures, Structural Dynamics and Materials Conference, La Jolla, CA, Apr. 1993, pp. 2240-2249.

8. Rouse, M. Effect of cutouts or low-speed impact damage on the postbuckling behaviour of composite plates loaded in shear. 31st AIAA/ASME/ASCE/AHS/ASC Structures, Structural Dynamics and Materials Conference, Long Beach, CA, Apr. 1990, pp. 877891.

9. Kim, YH, Noor, AK. Buckling and postbuckling of composite panels with cutouts subjected to combined loads. Finite Elements in Analysis and Design, 1996, 22: 163-185.

10. Eiblmeier, J, Loughlan, J. The buckling response of carbon fibre composite panels with reinforced cutouts, Composite Structures, 32 (1995): 97-113.

11. Pandey, R, Thakur, S, Ramanath, KS, Rao, KP. Stress concentration and stability studies in composite ribs with flanged cutouts. In: 2001 World MSC Aerospace Conference, Toulouse, France, September 24-26, 2001.

12. ESDU 85001. Elastic Stress and Strain Distributions around Circular Holes in Infinite Plates of Orthotropic Material (Applicable to Fibre Reinforced Composites).

13. ESDU 86003. Choice of reinforcement for a circular hole in a fibre reinforced laminate plate.

14. ESDU 75034. Initial buckling stress, maximum direct stress and shear strain of square plates in shear with central circular holes.

15. ESDU 80023. Buckling of rectangular specially orthotropic plates.

16. MIL-HDBK 5. Metallic Materials and Elements for Aerospace Vehicle Structures. December, 1998.

17. Eiblmeier, J. The Influence of Cutouts on the Buckling Response of Composite Panels. Ph.D. Dissertation. College of Aeronautics, Cranfield University. 1996.

18. Hadi, B.K., Buckling of anisotropic sandwich panels with and without holes, Centre for Composite Materials, 1995, University of London: London. 


\section{Figures}

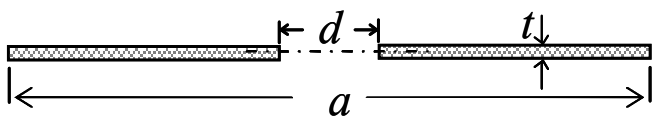

A-A section view

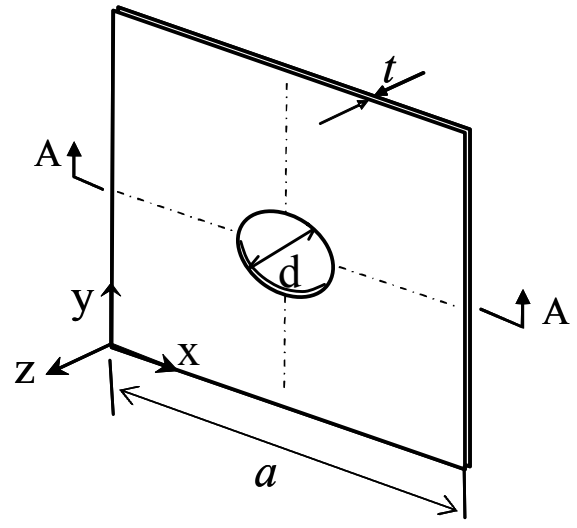

Figure 1 . The plate geometry with a central circular cutout

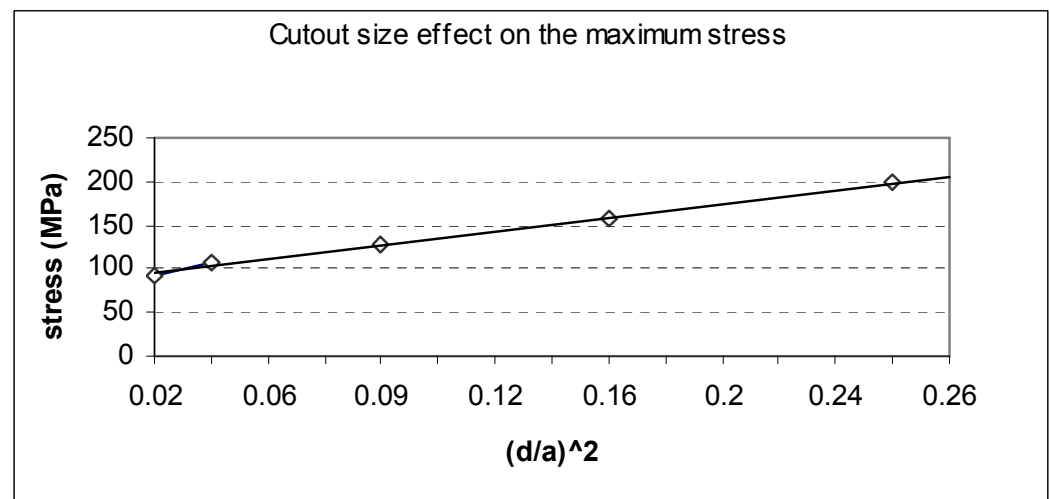

Figure 2. Variation of maximum stress against $(d / a)^{2}$

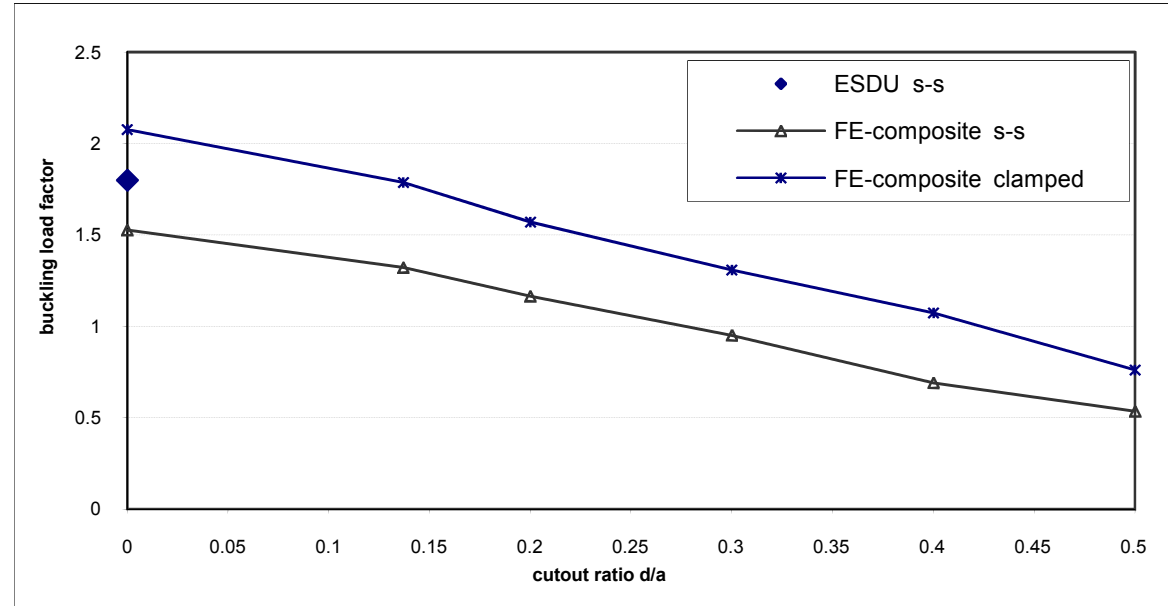

Figure 3. Variation of BLF of the composite plates against cutout ratio $d / a$ 


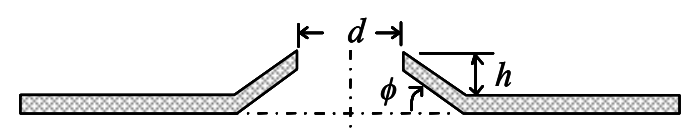

Type-1 - flange reinforcement

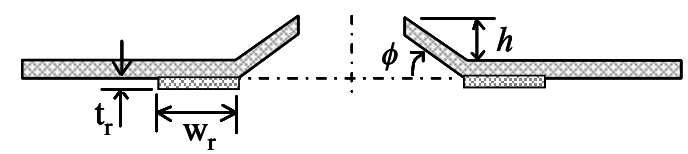

Type-3 - flange and ring reinforcement

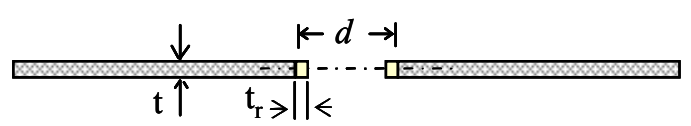

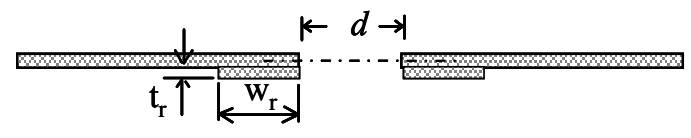

Type-2 - single ring reinforcement

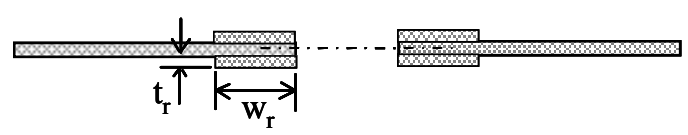

Type-4 - double ring reinforcement

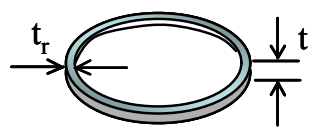

Type-5 - central tube reinforcement

Figure 4. Five types of cutout reinforcement

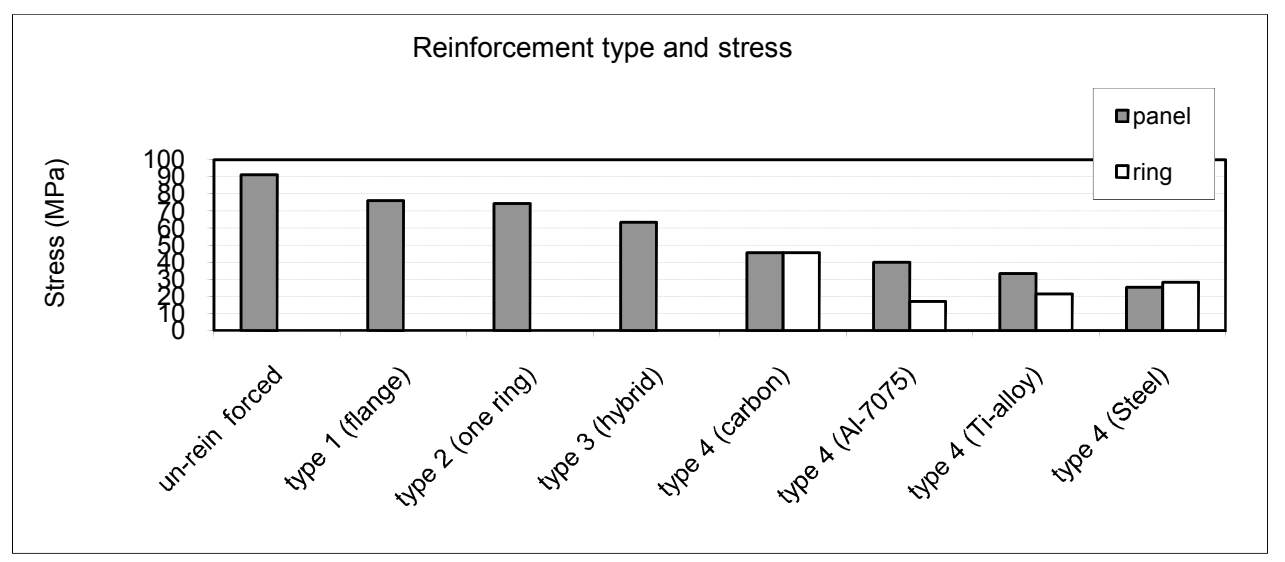

Figure 5. Maximum Stress comparison for different reinforcement types

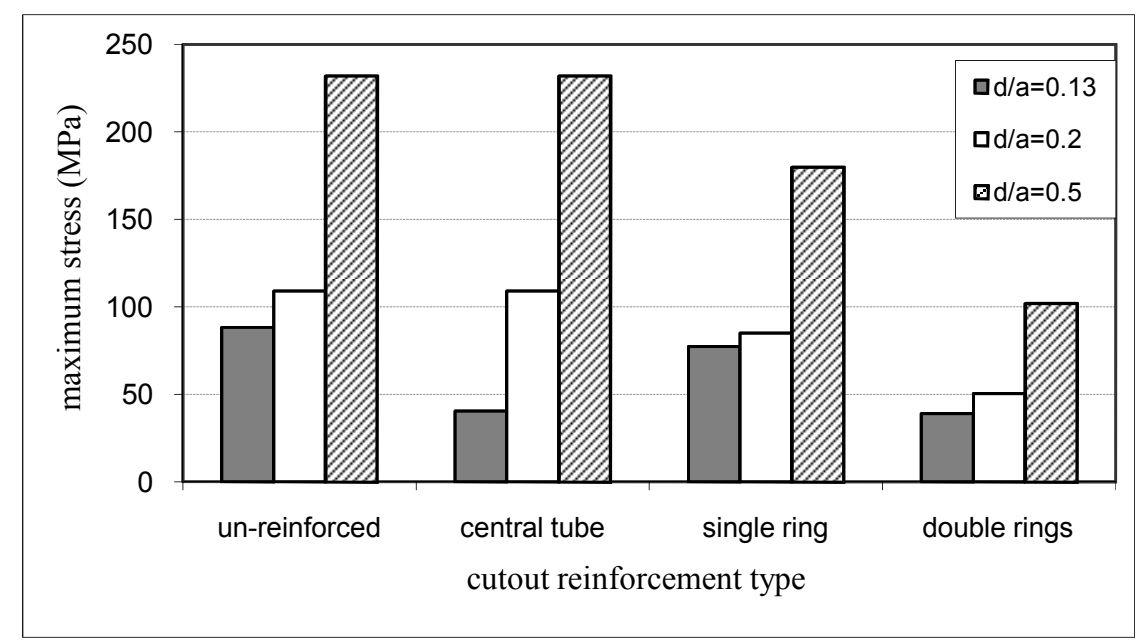

Figure 6. Maximum stress of a sandwich panel with different cutouts and reinforcements 

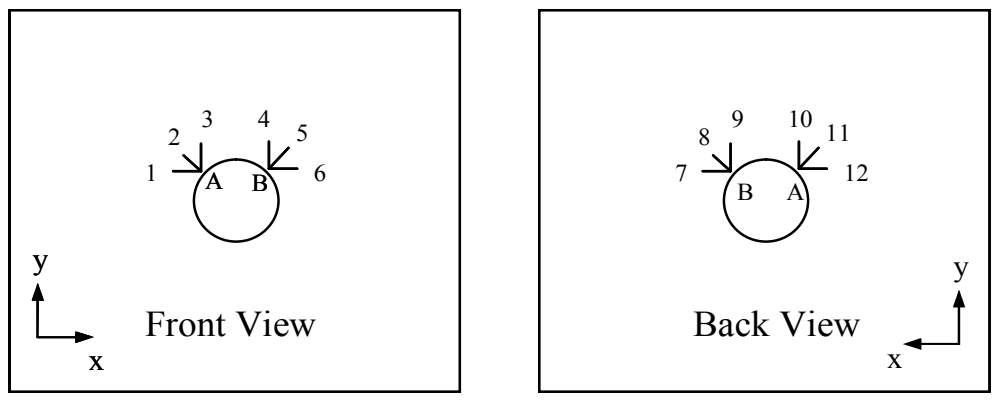

Figure 7. Strain gauge locations for test sample 1, 5 and 6
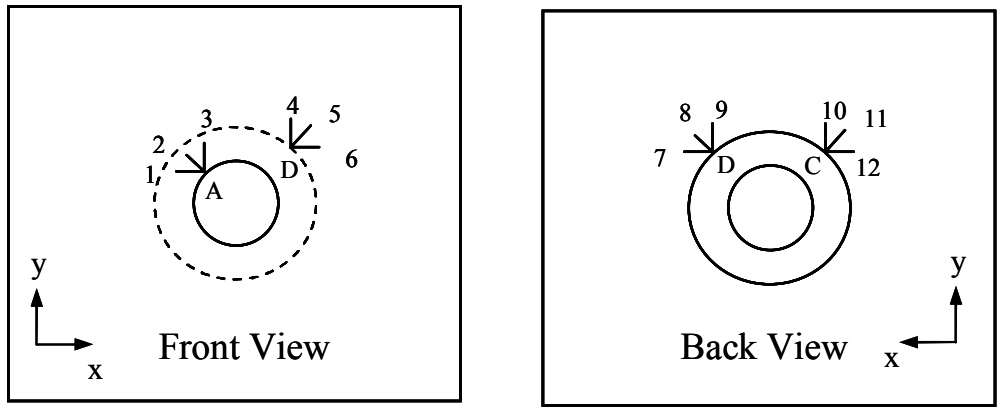

Figure 8. Strain gauge locations for test sample 2 with one ring

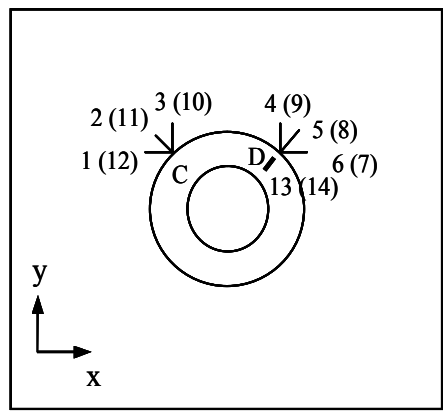

(a) test sample 3

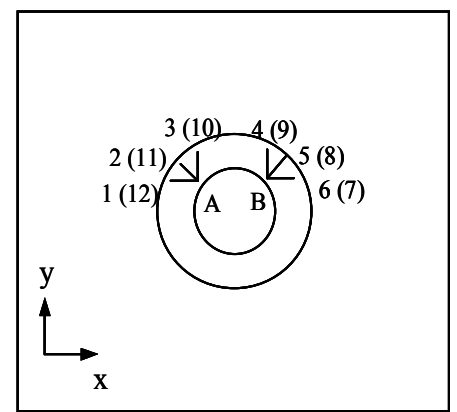

(b) test sample 4

Figure 9. Strain gauge locations for test sample 3 and 4 with two rings 


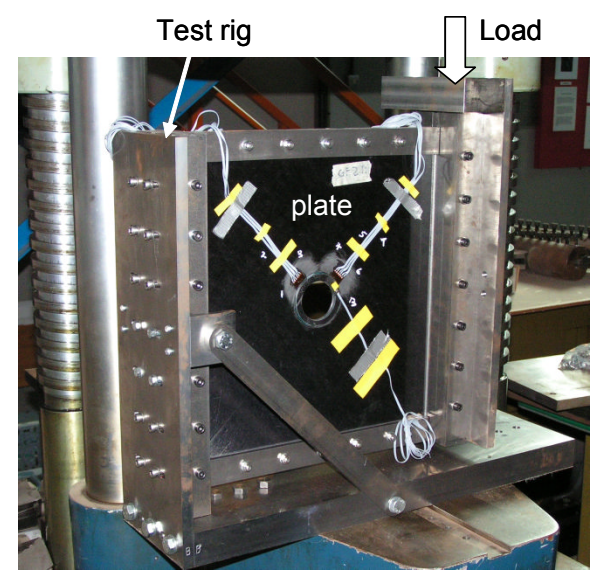

Figure 10. Test plate mounted to shear test rig and machine

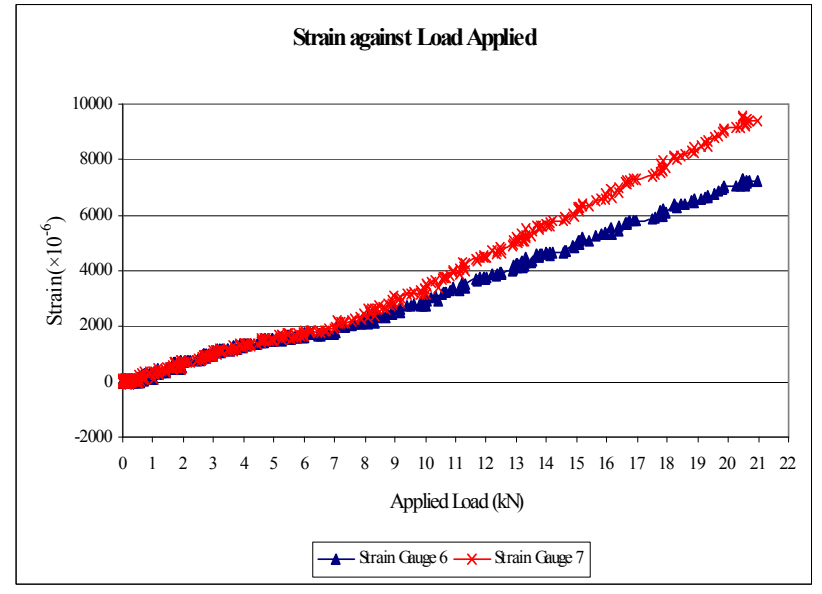

$\mathrm{X}$ direction

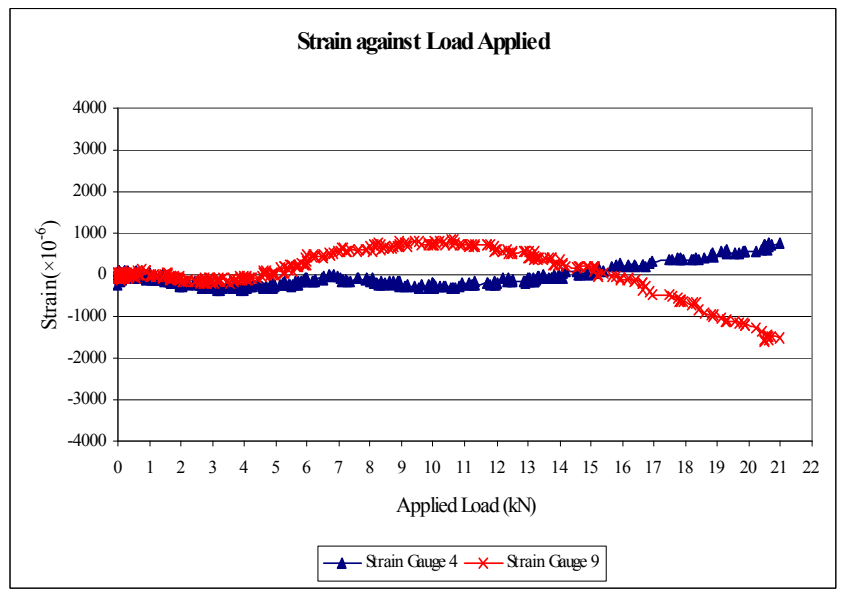

Y direction

Figure 11. Measured strain against applied loading in test sample 1 


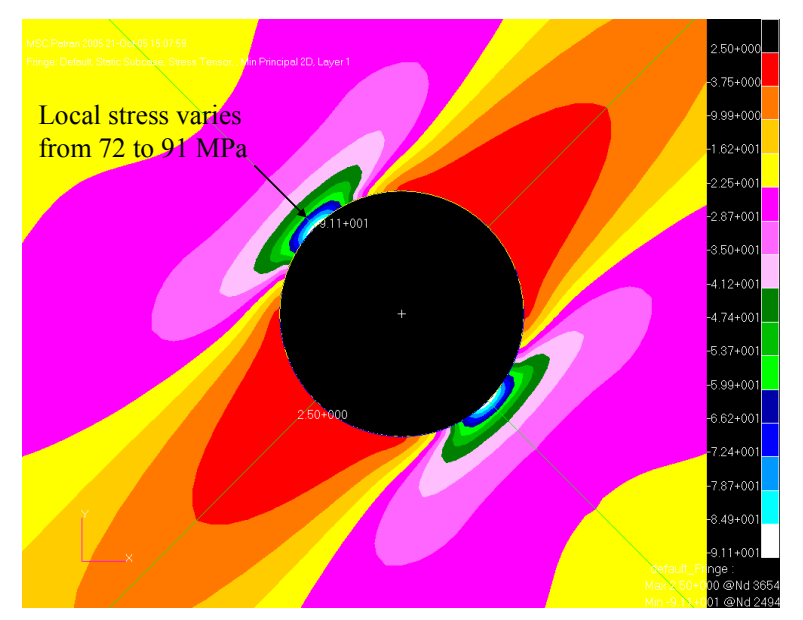

Figure 12. Stress distribution around the cutout without reinforcement

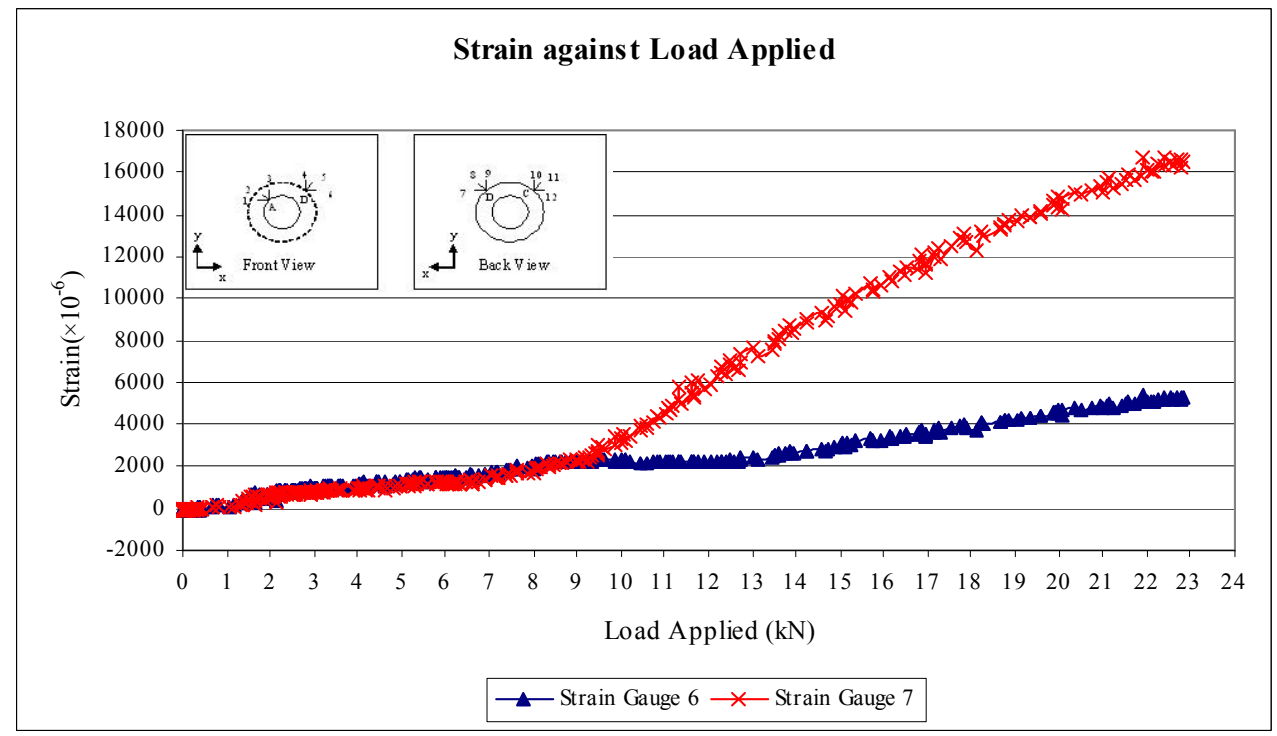

Figure 13. Measured strain against applied loading in test sample 2 


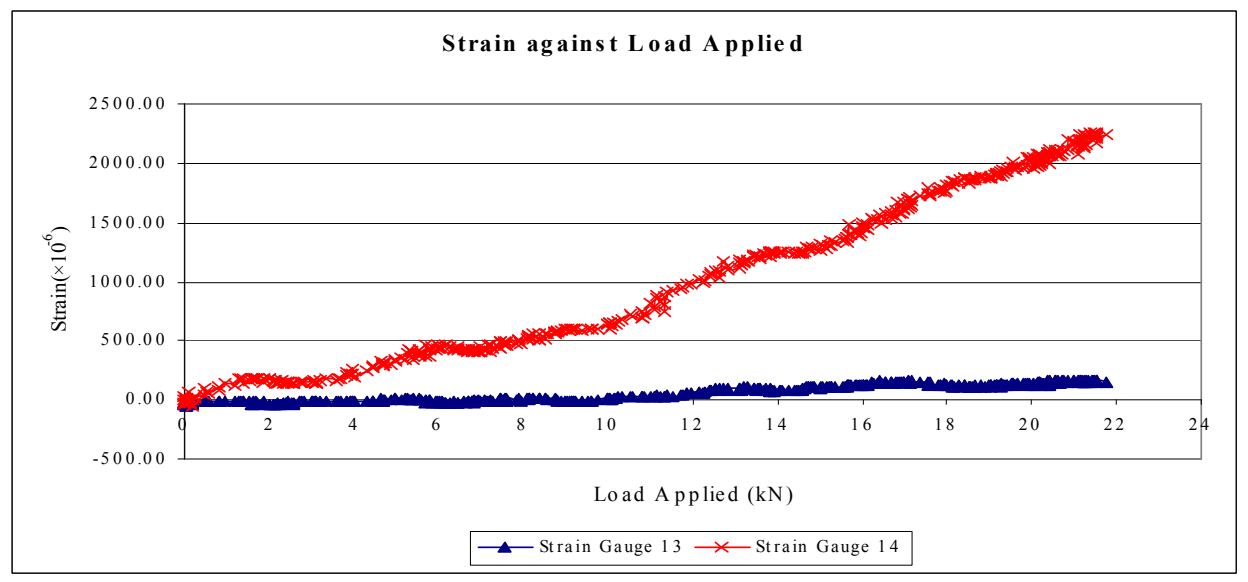

Figure 14. Measured strain against applied loading in test sample 3

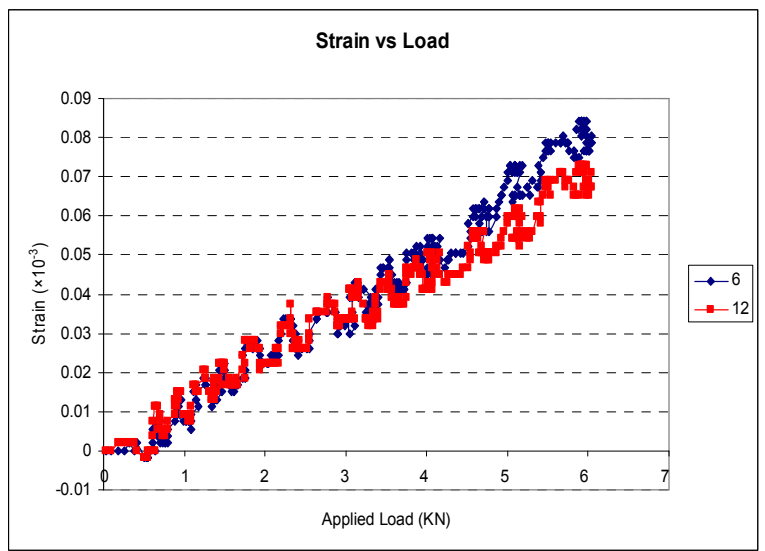

Test $\sigma_{\mathrm{x}}$

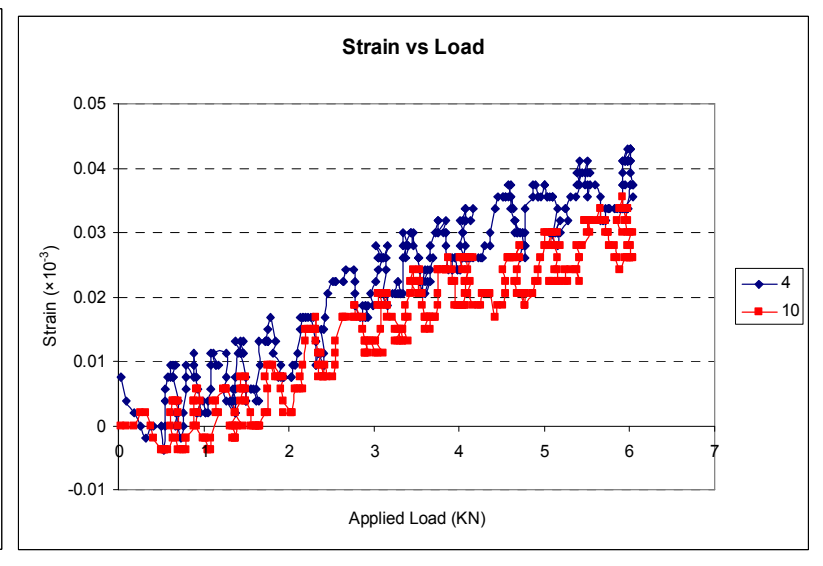

Test $\sigma_{\mathrm{y}}$

Figure 15. Measured strain against applied loading in test sample 4 


\section{Tables}

Table 1. Material properties for the composite panel examples

\begin{tabular}{l|c|c|c|c|c}
\hline & $\mathrm{E}_{11}(\mathrm{GPa})$ & $\mathrm{E}_{22}(\mathrm{GPa})$ & $\mathrm{G}_{12}(\mathrm{GPa})$ & $v_{12}$ & $\rho\left(\mathrm{kg} / \mathrm{m}^{3}\right)$ \\
\hline Example 1, 2 & 114.0 & 8.1 & 3.9 & 0.32 & 1560 \\
\hline Example 3 & 172.0 & 10.0 & 5.0 & 0.3 & 1580 \\
\hline AIREX C71 & $\mathrm{E}_{\mathrm{t}}=0.38$ & $\mathrm{E}_{\mathrm{c}}=0.07$ & $\mathrm{G}_{\mathrm{xy}}=0.02$ & 0.3 & 60 \\
\hline AIREX C75.71 & $\mathrm{E}_{\mathrm{x}}=0.06$ & $\mathrm{E}_{\mathrm{y}}=0.06$ & $\mathrm{G}_{\mathrm{xy}}=0.03$ & 0.32 & 80 \\
\hline
\end{tabular}

Table 2. Normal stress comparison between ESDU and FE models

\begin{tabular}{l|c|c|c}
\hline Method and models & ESDU-85001 & Quasi-isotropic FE & Laminate FE \\
\hline $\begin{array}{l}\text { Stress } \sigma_{\mathrm{x}}\left(=\sigma_{\mathrm{y}} \mathrm{MPa}\right) \\
\text { at position } \mathrm{A} \& \mathrm{~B}\end{array}$ & \pm 31 & \pm 26.2 & \pm 29.1 \\
\hline
\end{tabular}

Table 3. Maximum principle stress and BLF ratios with reinforcement type 1

\begin{tabular}{c|c|c|c|c|c}
\hline \multirow{2}{*}{$\begin{array}{c}\text { Cutout } \\
\text { ratio d/a }\end{array}$} & Flange angle $\phi(\mathrm{deg})$ & 32 & 32 & 45 & 45 \\
\cline { 2 - 6 } & Flange height $h(\mathrm{~mm})$ & 5 & 10 & 5 & 10 \\
\hline 0.1375 & Stress ratio & 0.869 & 0.906 & 0.851 & 0.835 \\
\hline 0.1375 & \multirow{2}{*}{$\begin{array}{c}\text { BLF ratio } \\
\text { (simply-supported) }\end{array}$} & 1.197 & 1.288 & 1.174 & 1.242 \\
\cline { 3 - 6 } & & 1.328 & 1.474 & 1.293 & 1.422 \\
\cline { 3 - 6 } 0.2 & 2.019 & 3.000 & 1.887 & 2.849 \\
\hline 0.5 & \multirow{2}{*}{$\begin{array}{c}\text { BLF ratio } \\
\text { (clamped) }\end{array}$} & 1.240 & 1.363 & 1.212 & 1.302 \\
\hline 0.1375 & & 1.376 & 1.554 & 1.338 & 1.490 \\
\hline 0.2 & & 2.066 & 3.066 & 1.908 & 2.882 \\
\hline 0.5 & & & & & \\
\hline
\end{tabular}


Table 4. Maximum stress and BLF ratios with reinforcement type 2

\begin{tabular}{c|c|c|c|c|c}
\hline $\begin{array}{c}\text { Cutout } \\
\text { ratio d/a }\end{array}$ & Ring width $\mathrm{w}_{\mathrm{r}}(\mathrm{mm})$ & 10 & 10 & 20 & 30 \\
\cline { 3 - 6 } & Ring thickness $\mathrm{t}_{\mathrm{r}}(\mathrm{mm})$ & 2 & 4 & 2 & 2 \\
\hline 0.1375 & Stress ratio & 0.936 & 0.870 & 0.855 & 0.816 \\
\hline 0.1375 & \multirow{2}{*}{$\begin{array}{c}\text { BLF ratio } \\
\text { (simply-supported) }\end{array}$} & 1.280 & 1.371 & 1.432 & 1.492 \\
\cline { 4 - 6 } 0.2 & 1.431 & 1.664 & 1.664 & 1.862 \\
\cline { 5 - 6 } 0.5 & & 1.962 & 3.245 & 2.528 & 3.094 \\
\hline 0.1375 & \multirow{2}{*}{$\begin{array}{c}\text { BLF ratio } \\
\text { (clamped) }\end{array}$} & 1.335 & 1.469 & 1.525 & 1.626 \\
\cline { 5 - 6 } & & 1.503 & 1.809 & 1.783 & 2.083 \\
\cline { 5 - 6 } 0.2 & & 2.013 & 3.289 & 2.579 & 3.145 \\
\hline
\end{tabular}

Table 5. Maximum stress and BLF ratios with reinforcement type 3

\begin{tabular}{|c|c|c|c|c|c|}
\hline \multirow{2}{*}{$\begin{array}{l}\text { Cutout } \\
\text { ratio } d / a\end{array}$} & Flange angle $\phi(\mathrm{deg})$ & 32 & 32 & 45 & 45 \\
\hline & Height h (mm) & 5 & 10 & 5 & 10 \\
\hline 0.1375 & Stress ratio & 0.811 & 0.712 & 0.759 & 0.697 \\
\hline 0.1375 & \multirow{3}{*}{$\begin{array}{c}\text { BLF ratio } \\
\text { (simply-supported) }\end{array}$} & 1.318 & 1.106 & 1.273 & 1.189 \\
\hline 0.2 & & 1.552 & 1.353 & 1.517 & 1.440 \\
\hline 0.5 & & 3.019 & 5.094 & 3.189 & 4.868 \\
\hline 0.1375 & \multirow{3}{*}{$\begin{array}{l}\text { BLF ratio } \\
\text { (clamped) }\end{array}$} & 1.391 & 1.156 & 1.313 & 1.229 \\
\hline 0.2 & & 1.656 & 1.484 & 1.605 & 1.548 \\
\hline 0.5 & & 3.092 & 5.513 & 3.197 & 4.855 \\
\hline
\end{tabular}

Table 6. Maximum stress and BLF ratios with reinforcement type 4

\begin{tabular}{c|c|c|c|c|c}
\hline Cutout & Ring width $\mathrm{w}_{\mathrm{r}}(\mathrm{mm})$ & 10 & 10 & 20 & 30 \\
\cline { 3 - 6 } Ratio d/a & Ring thickness $\mathrm{t}_{\mathrm{r}}(\mathrm{mm})$ & 2 & 4 & 2 & 2 \\
\hline 0.1375 & Stress ratio & 0.512 & 0.423 & 0.484 & 0.470 \\
\hline 0.1375 & \multirow{2}{*}{$\begin{array}{c}\text { BLF ratio } \\
\text { (simply-supported) }\end{array}$} & 1.356 & 1.379 & 1.409 & 1.477 \\
\cline { 4 - 6 } & & 1.621 & 1.672 & 1.741 & 1.862 \\
\cline { 4 - 6 } & & 2.906 & 5.434 & 4.245 & 5.792 \\
\hline 0.2 & \multirow{2}{*}{$\begin{array}{c}\text { BLF ratio } \\
\text { (clamped) }\end{array}$} & 1.447 & 1.447 & 1.508 & 1.609 \\
\cline { 3 - 5 } 0.1375 & & 1.758 & 1.809 & 1.924 & 2.121 \\
\hline 0.2 & & 2.947 & 5.513 & 4.316 & 5.842 \\
\hline 0.5 & & & & & \\
\hline
\end{tabular}


Table 7. Maximum principle stress at cutout edge reinforced by metallic rings

\begin{tabular}{c|c|c|c|c}
\hline Ring materials & Un-reinforced & AL7075 & Ti-Alloy & Stainless Steel \\
\hline Stress(MPa) & 91.1 & 39.9 & 33.4 & 25.3 \\
\hline
\end{tabular}

Table 8. Normalised maximum stress and $1^{\text {st }}$ BLF of reinforced laminated composite plates and un-reinforced sandwich panels against different cutout ratios

\begin{tabular}{|c|c|c|c|c|c|c|c|}
\hline & \multicolumn{4}{|c|}{ Laminated Composite Plates $\left[(+45 /-45)_{4}\right] \mathrm{s}$} & \multicolumn{3}{|c|}{ Composite Sandwich Panel } \\
\hline & $\begin{array}{r}16 \\
\text { CFR }\end{array}$ & & $\begin{array}{r}16 \\
\text { Stee }\end{array}$ & & $(1-5-1$ & $\begin{array}{l}\text { 8-c-8 ply } \\
\text { thickness }\end{array}$ & $\mathrm{mm}$ \\
\hline $\begin{array}{l}\text { Ratio } \\
\text { d/a }\end{array}$ & $\begin{array}{l}\text { Maximum } \\
\text { stress } \\
\text { ratio } \\
\text { (laminate) }\end{array}$ & $\begin{array}{c}1^{\text {st }} \mathrm{BLF} \\
\text { ratio }\end{array}$ & $\begin{array}{l}\text { Maximum } \\
\text { stress } \\
\text { ratio } \\
\text { (laminate) }\end{array}$ & $\begin{array}{c}1^{\text {st }} \mathrm{BLF} \\
\text { ratio }\end{array}$ & $\begin{array}{l}\text { Maximum } \\
\text { von Mises } \\
\text { stress } \\
\text { (foam) }\end{array}$ & $\begin{array}{l}\text { Maximum } \\
\text { stress } \\
\text { ratio } \\
\text { (laminate) }\end{array}$ & $\begin{array}{c}1^{\text {st }} \mathrm{BLF} \\
\text { ratio }\end{array}$ \\
\hline 0 & & & & & 0.012 & 1.000 & 3.637 \\
\hline 0.1 & 0.542 & 1.209 & 0.253 & 1.254 & 0.053 & 1.002 & 3.733 \\
\hline 0.1375 & 0.542 & 1.331 & 0.270 & 1.372 & 0.059 & 1.000 & 3.651 \\
\hline 0.2 & 0.547 & 1.561 & 0.323 & 1.666 & 0.069 & 1.039 & 3.420 \\
\hline 0.3 & 0.560 & 1.950 & 0.330 & 2.512 & 0.088 & 1.096 & 3.055 \\
\hline 0.4 & 0.554 & 2.373 & 0.329 & 4.254 & 0.106 & 1.079 & 2.867 \\
\hline 0.5 & 0.546 & 2.798 & 0.290 & 6.342 & 0.139 & 1.000 & 2.716 \\
\hline
\end{tabular}

Table 9. BLF ratio against cutout ratio for sandwich panels of constant weight

\begin{tabular}{|c|c|c|c|c|c|}
\hline \multicolumn{6}{|c|}{ BLF ratio for the sandwich panels of equivalent weight to the laminated composite plate } \\
\hline ratio & 7-c-7 ply & 6-c-6 ply & $5-c-5$ ply & 4-c-4 ply & 3-c-3 ply \\
\hline$d / a$ & $(0.88-6.5-0.88)$ & $(0.75-13-0.75)$ & $(0.63-19.5-0.63)$ & $(0.5-26-0.5)$ & $(0.38-32.5-0.38)$ \\
\hline 0 & 4.530 & 9.218 & 11.025 & 6.600 & 4.018 \\
\hline 0.1 & 4.447 & 8.077 & 4.742 & 2.323 & 1.019 \\
\hline 0.1375 & 4.259 & 7.293 & 4.258 & 2.082 & 0.935 \\
\hline 0.2 & 3.878 & 6.468 & 3.854 & 1.879 & 0.872 \\
\hline 0.3 & 3.492 & 5.835 & 3.571 & 1.735 & 0.840 \\
\hline 0.4 & 3.301 & 5.497 & 3.420 & 1.665 & 0.838 \\
\hline 0.5 & 3.131 & 5.180 & 3.257 & 1.596 & 0.827 \\
\hline
\end{tabular}


Table 10. Test samples for laminated and sandwich panels with different reinforcements

\begin{tabular}{|c|l|c|c|}
\hline \multicolumn{1}{|l|}{$\begin{array}{l}\text { Test sample } \\
\text { No }\end{array}$} & Reinforcement type & $\begin{array}{c}\text { width } \\
\mathrm{W}_{\mathrm{r}}(\mathrm{mm})\end{array}$ & $\begin{array}{c}\text { thickness } \\
\mathrm{t}_{\mathrm{r}}(\mathrm{mm})\end{array}$ \\
\hline 1 & Un-reinforced plate & 0 & 0 \\
\hline 2 & Type 2 (single CFRP ring) & 10 & 2 \\
\hline 3 & Type 4 (double CFRP rings) & 10 & 2 \\
\hline 4 & Type 4 (double steel rings) & 15 & 0 \\
\hline 5 & Un-reinforced sandwich panel & 0 & 2 \\
\hline 6 & Type 5 (central tube) & Depth $\mathrm{t}=9$ & \\
\hline
\end{tabular}

Table 11. Stress comparison of test data with FE results

\begin{tabular}{|c|c|c|c|c|c|c|}
\hline $\begin{array}{c}\text { Sample } \\
\text { No }\end{array}$ & $\begin{array}{c}\text { Measure } \\
- \text { ment } \\
\text { point }\end{array}$ & $\begin{array}{c}\text { Measured } \\
\varepsilon_{\mathrm{x}} \times 10^{-3}\end{array}$ & $\begin{array}{l}\text { Measured } \\
\varepsilon_{\mathrm{y}} \times 10^{-3}\end{array}$ & $\begin{array}{l}\text { Converted } \\
\text { stress } \sigma_{\mathrm{x}} \\
(\mathrm{MPa})\end{array}$ & $\begin{array}{l}\mathrm{FE} \sigma_{\mathrm{x}}(\mathrm{MPa}) \\
(\text { Constant } \\
\text { stress load })\end{array}$ & $\begin{array}{l}\mathrm{FE} \sigma_{\mathrm{x}}(\mathrm{MPa}) \\
(\text { Constant } \\
\text { displacement })\end{array}$ \\
\hline 1 & $\mathrm{~B}$ & 1.8 & 0.4 & 76 & 81.5 & 72.3 \\
\hline 2 & $\mathrm{D}$ & 1.1 & 0.2 & 45.1 & 40.1 & 41.8 \\
\hline 3 & $\mathrm{D}$ & 0.7 & 0.02 & 25.7 & 25.3 & 25.2 \\
\hline 4 & $\mathrm{~B}$ & 0.085 & 0.04 & 21.3 & 23.7 & 24 \\
\hline
\end{tabular}

Table 12. Buckling load comparison between experiment and FE results

\begin{tabular}{|c|c|c|c|}
\hline \multicolumn{4}{|c|}{ Buckling load (kN) Comparison } \\
\hline Test sample & Experiment & $\begin{array}{r}\text { FE buckling load } \\
\text { (Constant stress) }\end{array}$ & $\begin{array}{c}\text { FE buckling load } \\
\text { (Constant displacement) }\end{array}$ \\
\hline 1 & 8.5 & 8.4 & 8.3 \\
\hline 2 & 9.5 & 10.8 & 9.1 \\
\hline 3 & 10.0 & 11.5 & 11.9 \\
\hline 4 & 10.5 & 11.8 & 11.5 \\
\hline
\end{tabular}

